\title{
IMAGING PROCESSES OF WORKING MEMORY BY LOCALIZATION OF ACTIVATED FREQUENCY-SELECTIVE EEG GENERATORS
}

\begin{abstract}
Nina N. Danilova
Lomonosov Moscow State University

Moscow

The new method of microstructure analysis of oscillatory brain activity was proposed for studying the structure and dynamics of working memory. Mapping local network activity according to dipole localization of frequency-selective gamma and beta generators supports the leading role of frontal areas in processes of working memory. The retention of information during the delay interval is presented by joint activity of frequency-selective gamma and beta generators which provide the integration of frontal areas, associative, visual cortex and cerebellum. The joint activity of the gamma- and beta-generators has a wave-like character and is modulated by low-frequency wave activity.
\end{abstract}

Keywords: working memory, oscillatory brain activity, frequency-selective generator, equivalent dipole, pacemaker neuron.

New methods of brain activity mapping, such as Positron Emission Tomography (PET), and especially functional Magnetic Resonance Imaging (fMRI) along with spectroscopic imaging (MRS) that non-invasively reflect the brain activity, made a substantial contribution to the development of modern cognitive psychophysiology. The main achievement of the tomography methods is that they provide strong evidence of the systemic control of mental activity. It was demonstrated that patterns of activity foci and their defaults distributed throughout the brain space are specifically connected with a performed mental function (Corbetta \& Shulman, 2002; Posner, 2004; Mantini, Perrucci, Del Gratta, Romani, \& Corbetta, 2007; Corbetta, Patel, \& Shulman, 2008).

However, a significant deficiency of the tomography methods is their relatively low temporal resolution, which does not allow to investigate both the dynamics inside an activated locus and the rapidly changing interactions between the activated brain areas. 
High temporal resolution required for the study of the dynamics of mental processes is provided by the EEG and MEG recording methods, but they have their limitations as well. Specifically, MEG is capable of measuring cortical activity only, while EEG seems to be scarcely conductive to distinguishing between the processes that occur in the cortex and subcortical brain structures. Factor analysis applied to multichannel EEG recordings does not completely address this problem either.

How can local neural network activity be found by means of multichannel EEG data? One way to approach this challenge is to consider high-frequency electrical activity of brain, namely, a gamma rhythm that covers a frequency range of from 30 to $200 \mathrm{~Hz}$, and even up to $600 \mathrm{~Hz}$, as suggested by some papers (Sannita, 2000).

A high correlation between the gamma rhythm and psychological processes, as well as its recording in various brain structures of humans and animals, including invertebrates, allows to interpret the gamma oscillations as a functional building block of sensory, cognitive, and executive functions (Basar, 1999; Basar, Basar-Eroglu, Karakas, \& Schurman, 2000).

An important feature of oscillatory brain activity is its ability to ensure spatial-temporal synchronization, as well as synchronization with a stimulus or an event evoking a response. It should be noted that the discovery of the phenomenon of spatial-temporal synchronization of oscillatory activity is associated with M.V. Livanov (1972). In his experiments on cats he succeeded to demonstrate that learning animals leads to increase in synchronization of a theta-rhythm recorded from the cortex and reticular formation. Afterwards, spatial-temporal synchronization was repeatedly observed at the frequency of gamma oscillations in human and animal brain activity.

In order to understand the synchronization mechanism of gamma oscillations itself, it will be requisite to examine how the gamma-rhythm is actually generated.

According to the concept of binding, the gamma-rhythm occurs due to feedback and horizontal links between neurons that temporarily form an ensemble, a system of interlinked cells. Stimulus-specific synchronization at high frequencies $(35-90 \mathrm{~Hz})$ has been demonstrated in the cat visual cortex neurons.

Even though the concept of spatial-temporal binding seems so attractive, some experimental data fail to agree with it. In investigations 
by Singer and Gray (1995), neurons-detectors of the cat visual cortex spatially separated from each other at $7 \mathrm{~mm}$ manifest synchronization of gamma-oscillations at a zero-phase lag. This means that synchronization of gamma-oscillations does not necessarily imply a sequential transmission of a signal from one neuron to another.

An alternative hypothesis is based on the concept of an intracellular gamma-rhythm origin and presumes that rhythmical activity of a neuron totally isolated from other cells is still maintained (Grechenko \& Sokolov, 1979; Sokolov, 1981).

Neurons having endogenous rhythmical activity are generally referred to as pacemaker neurons. A pacemaker mechanism in such neurons interacts with a chemical-excitation and electro-excitation membrane and thereby transforms the neuron into a device with a "built-in controlled generator" (Sokolov \& Nezlina, 2007). These intracellular generators are responsible for the gamma-rhythm generation (Sokolov, 2003).

An important property of pacemaker neurons is their response to external stimuli. Postsynaptic potentials coming to a pacemaker neuron can induce a shift of the pacemaker wave phase causing it to reset. As a result, the pacemaker wave of endogenous origin is synchronized with external stimuli.

Pacemaker neurons have a characteristic of plasticity (Grechenko, 2008) which allows these neurons to work at various frequencies and to become a part of various neural networks. These properties make pacemaker neurons unique in terms of controlling other neurons.

It has been recently demonstrated that neurons with pacemaker properties are widely represented in a variety of brain structures and involved in various psychical functions. They were found in the neocortex, thalamus, hippocampus, cerebellum, and inferior olive.

\section{Methods}

Examination of the effects deriving from the pacemaker hypothesis of gamma-rhythm origin resulted in creation of the following research paradigm that has become known as a method of microstructure analysis of oscillatory brain activity (Danilova, 2005; Danilova, Bykova, Pirogov, \& Sokolov, 2005; Danilova, 2006). First, the method was applied exclusively to the gamma rhythm $(30-75 \mathrm{~Hz})$, but further it was extended 
to the beta-oscillations range $(14-30 \mathrm{~Hz})$. This method includes the following aspects:

1. A repeated sensory stimulus enables to obtain an averaged eventrelated potential (ERP) for each channel of the brain activity recording.

2. Frequency components in the range of $14-75 \mathrm{~Hz}$, the so-called evoked oscillations, are separated from the ERP by a narrow-band frequency filtering method at a $1 \mathrm{~Hz}$ step; the components are phase-synchronized with a stimulus which meets the characteristics of pacemaker neurons.

3. An equivalent dipole is localized in brain structures for each oscillation frequency based on 15-channel ERP recording data.

4. Location of each equivalent dipole of narrow-band oscillations in brain is superimposed onto a respective "slice" of a structural MRI scan obtained for each participant.

5. Time distribution of equivalent dipoles that differ in frequency and location is analyzed in a selected ERP time window and in an interval preceding the stimulus.

6. A sum of localized equivalent dipoles is used as a measure of narrow-band oscillation activity for a selected ERP time window (Fig. 1).

The findings of a research in working memory processes performed by the method of microstructure analysis of oscillatory brain activity are provided below.

The research covered 10 subjects aged 20-23. A subject had to memorize four pairs of two-digit numbers (St1) and to retain them in memory during a delay interval for subsequent comparison with stimuli (St2 or St3) containing a single two-digit number. The delay interval was $5 \mathrm{~s}$. Exposure time for each stimulus accounted for $1 \mathrm{~s}$. A response to stimulus St2 must be a motor reaction, because it coincided with one of the St 1 numbers and was a target. St 3 was a discriminative stimulus. The numbers to be memorized were never repeated. EEG was recorded by a Brainsys computer system manufactured by NMF Statokin (Russia). The experiment included 15-channel EEG recording according to the international system (10-20\%) with O2, O1, P4, P3, C4, C3, CZ, T6, T5, T4, T3, F4, F3, F8, F7 leads. A combined ear electrode served as a 
1

St

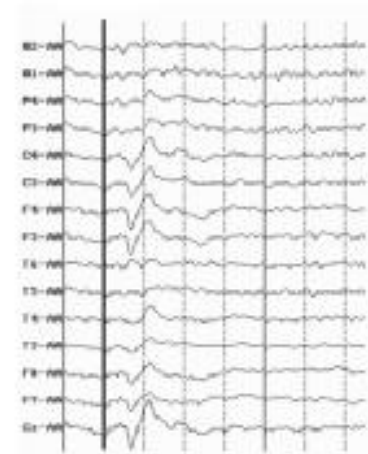

3

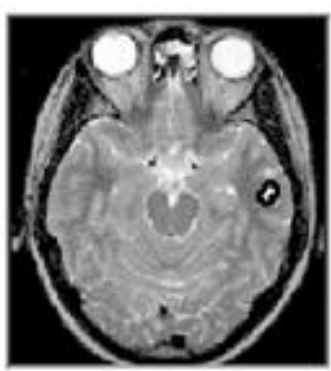

St

2

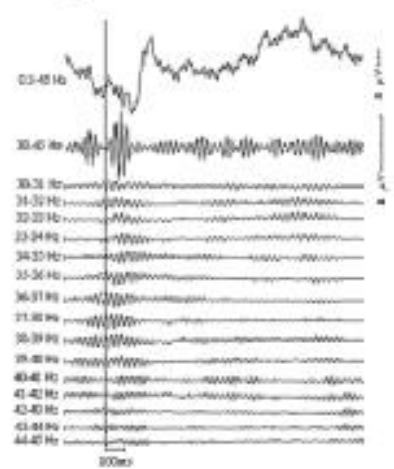

4

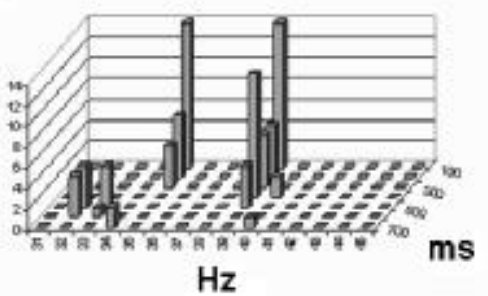

Figure 1. 4 stages of microstructure analysis of oscillatory brain activity: 1. ERP; 2. Narrow band frequency filtering event-related potentials (ERP) with $1 \mathrm{~Hz}$ step in the gamma and beta ranges (ER-oscillations); 3. Location of current dipoles for narrow band oscillations over axial slices received by structural MRI; 4. The amount of current dipoles within certain time window is used as a measure of frequency-selective generators activity.

referent. An EEG digitizing frequency was $400 \mathrm{~Hz}$. A bandwidth was between 0.3 and $80 \mathrm{~Hz}$. A band-rejection filter was employed at $50 \mathrm{~Hz}$. An averaged event-related potential (ERP) was calculated for each type of stimuli and then was processed through the microstructure analysis method including narrow-band frequency filtration at a $1 \mathrm{~Hz}$ step in the beta- and gamma-rhythm band. The Brainloc software (a single tracing dipole model) calculated coordinates of equivalent dipoles for isolated oscillations. At an EEG digitizing frequency of $400 \mathrm{~Hz}$ search for the 
presence of a dipole source was performed every $2.5 \mathrm{~ms}$. Coordinates of the oscillation sources calculated according to the 15-channel EEG with a dipole coefficient of 0.95 were projected onto the structural MRI brain scans of specific subjects. These scans were made on the TOMIKON S50 (BRUKER) Magnetic Resonance Imaging machine at the Moscow State University Center of Magnetic Resonance Tomography and Spectroscopy.

Brain localization of equivalent dipole sources of activated frequency selective gamma and beta generators was analyzed to map brain structures containing the activated generators.

\section{Results}

The experiments involving working memory tasks have shown high activity of the frontal brain. Activation of the frontal cortex occurs both within the interval of presentation of numbers to be memorized and within the delay interval as well. In addition to the frontal parts of the brain, activation also involved the associative (temporal, parietal) cortex, sensory visual cortex, and cerebellum. Activity of the four above-mentioned structures is predominant both during number presentation and during the delay interval. Only a small number of dipoles are localized in the thalamus and hippocampus areas.

Based on the number of localized equivalent dipoles of gamma and beta generators, an average level of total brain activity during the perception and memorization of numbers is two times higher than during the delay interval. The activity in the frontal cortex increases by the end of the number presentation (as shown in Fig. 2).

According to group data received from the working memory experiments, $32.9 \%$ of the overall number of dipoles was generated in the frontal lobe. Activity of the association and parietal cortex, and the cerebellum, measured by the number of localized dipoles and expressed as a percentage of their total sum, equals $28.3 \%, 20.5 \%$ and $18.2 \%$, respectively. During the delay interval, the peak of activity moves from the frontal to the association cortex (34.1\%) and the cerebellum (29.2\%). The frontal areas and visual cortex are also involved but to a less extent, as represented by fewer localized dipole sources $(18.7 \%$ and $17.9 \%$ respectively). 


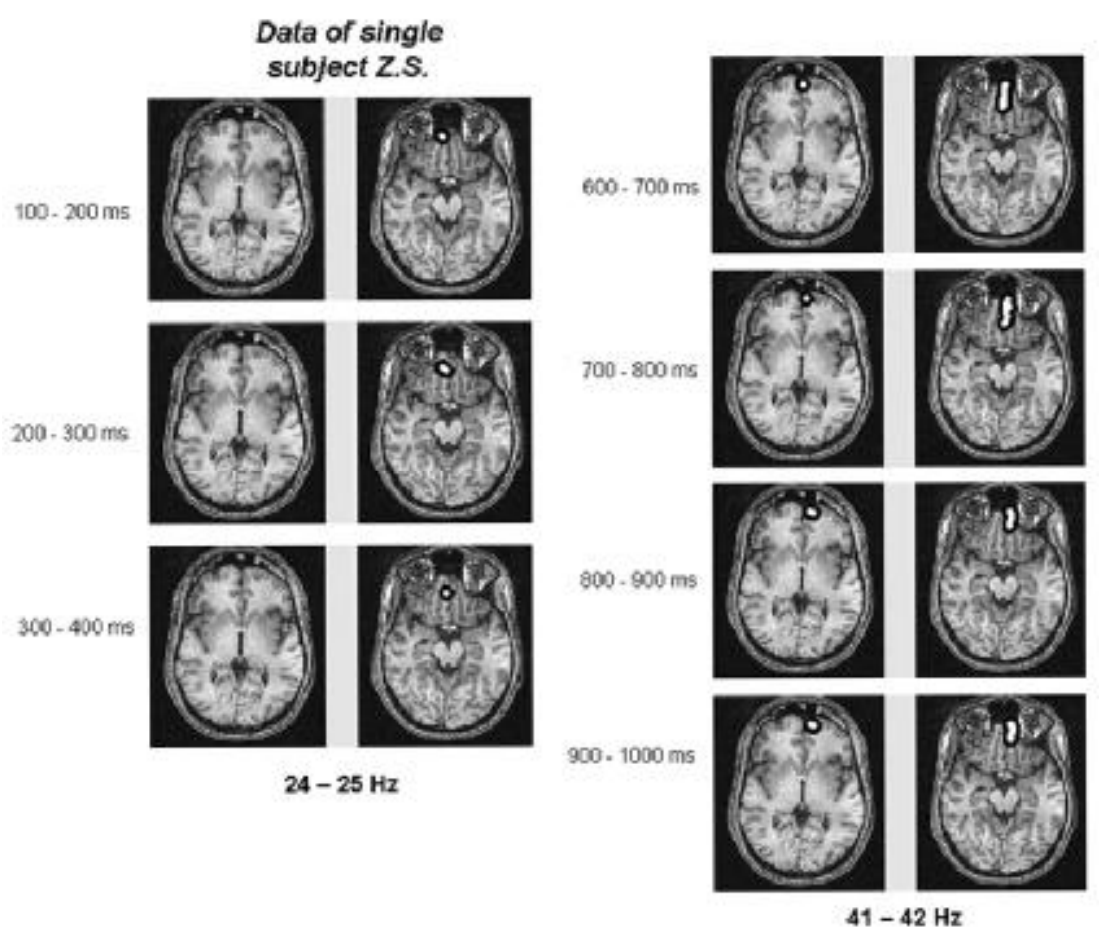

Figure 2. Stable location of current dipoles of frequency - selective gamma and beta generators in frontal system during perception of numbers (St1). Subject Z.S.

Shift of the activity from the frontal to the association cortex within the delay interval supports the hypothesis that information from the association areas of the brain can be rewritten into the prefrontal cortex. This makes this operation an important link for information retention in memory. The growth of cerebellum activity within the delay interval, as was discovered in these experiments, may be attributed to a motor readiness response and ability to predict the moment of presentation of the eliciting stimulus. A similar effect was observed during recurrent performance of one and the same motor task in response to auditory stimuli presented at fixed time intervals (Danilova \& Bykova, 2003a; 2003b). 


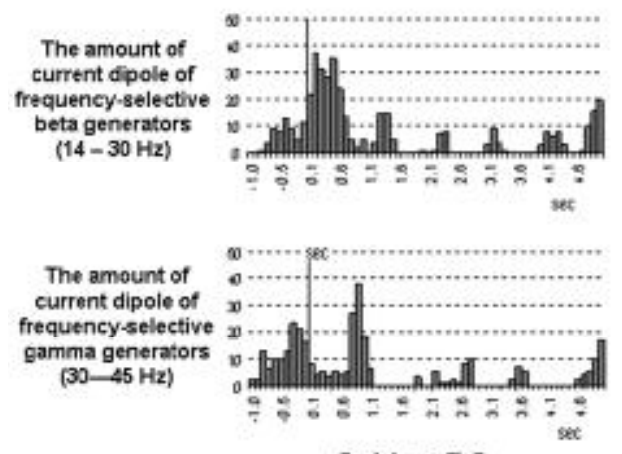

Subject Z.S.
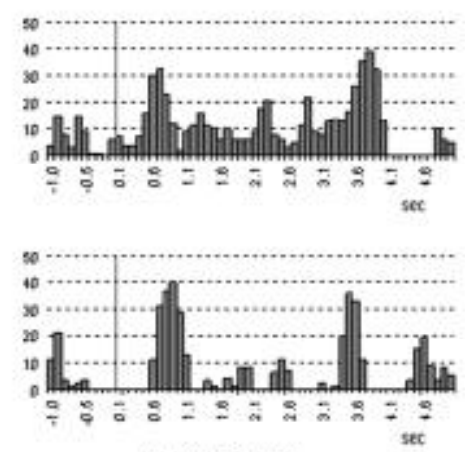

Subject S.M.

Figure 3. Time histograms of the current dipoles of frequency-selective beta and gamma generators after Stl during delay interval show periodic activity of generators.

On the ground of the foregoing, an assumption can be made that motor memory traces, in addition to sensory memory traces, are activated during the delay interval.

The research has demonstrated that memory trace retention within the delay interval requires high activity of a subject. In this case, the frequency-selective generators operating at different frequencies generate bursts of joint activity that appear and disappear from time to time. Their activity modulation frequency is about $1 \mathrm{~Hz}$. Fig. 3 depicts the time-distribution histograms for the total of equivalent dipoles of gamma and beta generators within ERPs recorded for stimulus St1, which is visual presentation of four digits to be memorized. The ERP duration is $6 \mathrm{~s}$, including $1 \mathrm{~s}$ prior to stimulus presentation, $1 \mathrm{~s}$ during its presentation, and a $4 \mathrm{~s}$ delay interval. The time scale is subdivided into quanta of $100 \mathrm{~ms}$ each. Each quantum represents a sum of all localized equivalent dipoles that map the activity of frequency-selective generators in two frequency bands: beta (A) and gamma (B) regardless of their localization in brain. The histograms demonstrate well-defined fluctuations of frequency-selective generator activity measured by the number of the localized dipoles.

Each wave of growth in the number of dipoles corresponds to a specific pattern of the brain activity foci. Fig. 4 shows activity loci for all 
three generators activated during growth in the dipole number from 3300 to $3700 \mathrm{~ms}$ after onset of the St1 stimulus. A stable correlation between each generator and a respective structure the same is bound to, which can be maintained within $200-300 \mathrm{~ms}$, is apparent. Joint activity of generators localized in various brain structures can be regarded as formation of a system supporting interactions of spatially separated local networks. Their system integration is achieved through a special type of synchronization of oscillatory activity of different frequencyselective generators that is based on low frequency modulation from another source. Fluctuations of this type were found in the hemodynamic signal when dealing with fMRI. As a result of visual spatial attention studies in humans and monkeys, the authors could identify a system for goal-directed attention and a default system (Corbetta, Patel, \& Shulman, 2008). The systems have a reciprocal relationship: the activity of one system is replaced by the activity of another from time to time. The authors view this process as a manifestation of behavioral

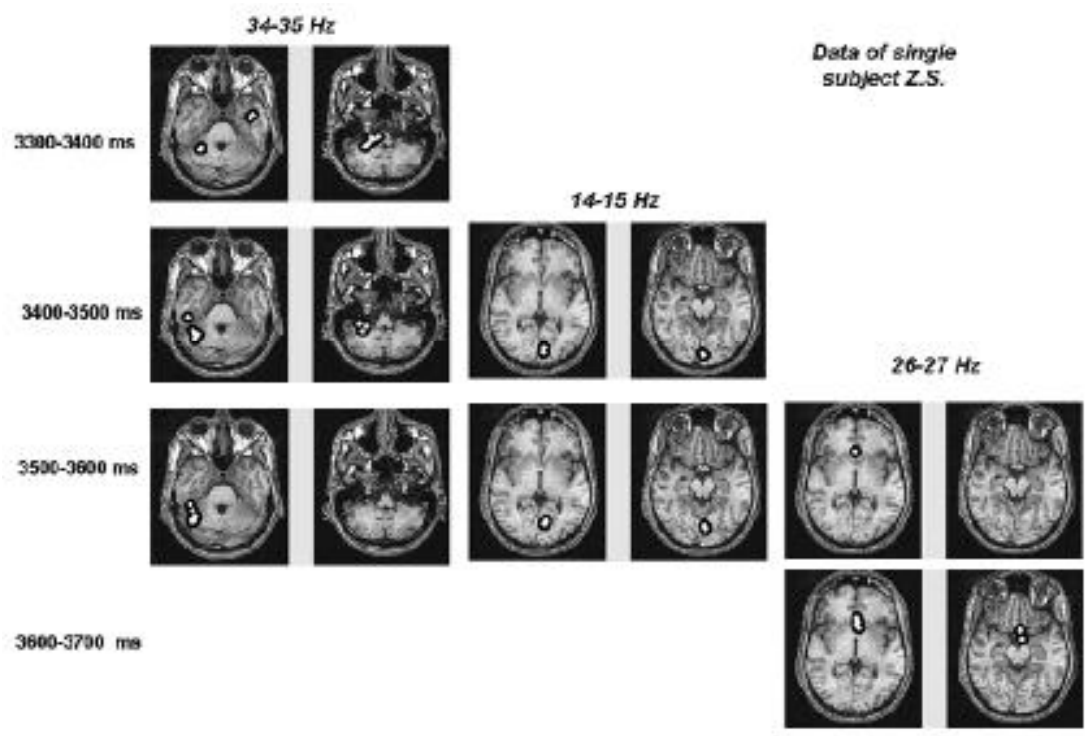

Figure 4. Parallel activity of frequency-selective gamma and beta generators located in different brain structures at delay interval (3300-3700 ms). 
competition between task-focused attention and the processes that service events and thoughts irrelevant to the task. They attribute fluctuations in the hemodynamic signal to oscillatory activity of neuronal assemblies, including ultra-slow fluctuations in the overall strength of the gamma-rhythm.

It should be noted that joint activity of frontal brain areas along with the visual and temporal cortices occurs within the delay interval and is absent during the perception of numbers. These facts seem to be consistent with the hypothesis that interaction of local networks within a delay interval facilitates rewriting the numerical information from the association brain areas into the prefrontal cortex, where such information turns into an active form ready for subsequent use in behavior (Goldman-Rakic, 1996). A novel aspect lies in that the modality-specific visual cortex is involved in the interaction between the prefrontal and association cortex.

In the investigation of the EEG mapping of activated memory traces, attention is basically paid to of theta-rhythm oscillations $(4-7 \mathrm{~Hz})$ which are amplified during memory operations. At the same time, many researchers emphasize either absence of any correlation between gamma-oscillations and memory trace activation, or lack of data on relations between gamma-oscillations and working memory processes (Sarnthein, Petsche, Rappelsberger, Shaw, \& von Stein, 1998; Jensen \& Tesche, 2002; Sauseng et al., 2007). Our results associated with the activation of frequency-selective generators operating within the delay interval at the gamma and beta rhythm frequencies point to the involvement of high-frequency oscillations in working memory processes; this is concerted with the results obtained (Tallon-Baudry, Kreiter, \& Bertrand, 1999) through the wavelet analysis. Traditionally, amplification of the gamma-rhythm is associated with increase in attention. We would like to propose another explanation. Amplified activity of the frequency-selective gamma and beta generators is a manifestation of a local form of activation that may occur in neural networks performing various functions and containing pacemaker neurons. It is generally known that operations with numerical data involve both shortterm and long-term memory. Therefore, it can be assumed that joint activation of frequency-selective gamma and beta generators reflects a mechanism that transfers long-term memory traces associated with 
numbers into short-term working memory and retains the activated memory traces within the delay interval.

An activated engram has its own electrical equivalent. A frequencyselective gamma or beta generator reflecting work of pacemaker neurons of a local neural network may serve as such an equivalent.

Joint activity of the gamma and beta generators that occurs periodically points to a wave-like character of this process. Interaction between local neural networks of the temporal, prefrontal, and visual cortex begins from the onset of joint activity. It is achieved through time-synchronization of oscillatory activity of the frequency-selective generators operating at different frequencies. The joint activity of gamma and beta generators is modulated by low-frequency wave activity (Danilova, 2005; Danilova \& Bykova, 2003b). Other researchers (Sauseng, Hoppe, Klimesch, Gerloff, \& Hummel, 2007; Sauseng, Klimesch, Gruber, \& Birbaumer, 2008) have reached the same conclusions regarding the integration of different-frequency oscillations. However, their conclusion is based on calculations of phase-synchronization between theta- and gamma-oscillations recorded for selected pairs of electrodes. In our investigation we are concerned with analyzing synchronous oscillatory activity of frequency-selective generators, which localization in brain is determined by multi-channel EEG recordings. Moreover, the aforementioned generators reflect activity of pacemaker neurons incorporated into local neural networks.

For this reason it is possible to talk about two mechanisms facilitating the system integration of local neural networks. One mechanism is joint activity of frequency-selective gamma and beta generators operating at different frequencies that temporarily synchronize their wave activity. The other integration mechanism we have shown above presumes arrangement of local networks into a system by generating oscillations at a common frequency phase-synchronized with a stimulus. This type of mechanism was demonstrated during sensory response and anticipation reaction in the auditory stimulation experiments under active attention, when activity loci in the frontal and modality-specific cortex generated oscillations at a single frequency (Danilova \& Bykova, 2003a; 2003b). Controlling local networks by altering frequency and phase characteristics of oscillatory brain activity appears to be an efficient brain mechanism. 


\section{Conclusion}

A new experimental approach based on the pacemaker hypothesis of high-frequency EEG rhythms origin was proposed for studying structure and dynamics of cognitive processes. This approach has been used to develop a method for microstructure analysis of oscillatory brain activity including narrow-band frequency filtering of event-related potentials (ERP), calculation of equivalent current dipoles based on multichannel EEG data, and their superimposition onto structural Magnetic Resonance Imaging scans of an individual brain.

The described method identified frequency-selective gamma and beta generators mapping activity of pacemaker neurons in local networks as a new electroencephalographic index of local neural network activity. A frequency-selective generator is able to adjust selectively its frequency. Its activity can be measured by a total of localized equivalent dipoles and characterized by temporal and spatial discreteness (Danilova, 2005; Danilova et al., 2005; Danilova, 2006).

Mapping of local network activity according to localization data relative to frequency-selective gamma and beta generators supports the leading role of frontal areas in processes of working memory. Activity shift from the frontal to the associative cortex occurs within the delay interval. Retention of information within the delay interval is represented by joint activity of frequency-selective gamma and beta generators and provides for integration of frontal areas, associative, visual cortex and cerebellum. Joint activity of the gamma and beta generators has a wave-like character due to rhythmic low-frequency modulation.

\section{References}

Basar, E. (1999). Brain Function and Oscillations: Volume II: Integrative Brain Function. Neurophysiology and Cognitive Processes. Berlin, Heidelberg: Springer.

Basar, E., Basar-Eroglu, C., Karakas, S., \& Schurman, M. (2000). Brain Oscillation in Perception and Memory. International Journal of Psychophysiology, 35, 95-124.

Corbetta, M., \& Shulman, G.L. (2002). Control of Goal-Directed and StimulusDriven Attention in the Brain. Nature Reviews Neuroscience, 3, 201-215.

Corbetta, M., Patel, G., \& Shulman, G.L. (2008). The Reorienting System of the Human Brain: From Environment to Theory of Mind. Neuron, 58, 306-324. 
Danilova, N.N. (2005). Častotnaâ specifičnost' oscillâtorov gamma-ritma [Frequency Specificity of Gamma-Rhythm Oscillators]. Rossijskij psihologičeskij žurnal, $3(2), 35-60$.

Danilova, N.N. (2006). Rol' vysokočastotnyh ritmov èlektričeskoj aktivnosti mozga $\mathrm{v}$ obespečenii psihičeskih processov [The Role of High-Frequency Electrical Brain Activity in Realization of Psychological Processes]. Psihologiâ. Žurnal vyš̌sej školy èkonomiki, 3 (2), 62-72.

Danilova, N.N., \& Bykova, N.B. (2003a). Rol' častotno-specifičeskih kodov v processah vnimaniâ [The Role of Frequency-Specific Codes in Attention Processes]. In T.V. Akhutina \& J.M. Glozman (Eds.), Doklady vtoroj Meždunarodnoj konferencii, posvâsennoj 100-letiû so dnâ roždeniâ A.R. Luriâ [Proceeding of the Second International Luria Memorial Conference] (pp. 290-295). Moscow: Smysl.

Danilova, N.N., \& Bykova, N.B. (2003b). Oscillâtornaâ aktivnost' mozga i informacionnye processy [Oscillatory Brain Activity and Information Processes]. In A.L. Zhuravlev \& N.V. Tarabrina (Eds.), Psihologiâ. Sovremennye napravleniâ meždisciplinarnyh issledovanij [Psychology. Modern Trends of Interdisciplinary Researches] (pp. 271-283). Moscow: IP RAN.

Danilova, N.N., Bykova, N.B., Pirogov, Yu.A., \& Sokolov, E.N. (2005). Issledovanie častotnoj specifičnosti oscillâtorov gamma-ritma metodami dipol'nogo analiza i anatomičeskoj magnitno-rezonansnoj tomografii [Investigation of Frequency-Specific Gamma Oscillators by Dipole Analysis Method and Structural Magnetic Resonance Tomography]. Biomedicinskie tehnologii i radioèlektronika, 4-5, 89-97.

Eckhorn, R., Bauer, R., Jorden, W., Brosch, M., Kruse, W., Munk, M.H.J., \& Reitboeck, H.J. (1988). Coherent Oscillations: A Mechanism of Feature Linking in the Visual Cortex? Multiple Electrode and Correlation Analysis in the Cat. Biological Cybernetics, 60, 121-130.

Goldman-Rakic, P.C. (1996). Regional and Cellular Fractionation of Working Memory. PNAS, 93 (24), 13473-13480.

Grechenko, T.N. (2008). Pejsmekernaâ aktivnost' nejronov: proishoždenie i funkcii [Pacemaker Neuron Activity: Origin and Functions]. In E.N. Sokolov, V.A. Filippov, \& A.M. Chernorizov (Eds.), Nejron. Obrabotka signalov. Plastičnost'. Modelirovanie [Neuron. Signal Processing. Plasticity. Simulation] (pp. 324-432). Tyumen: Izdatel'stvo Tûmenskogo gosudarstvennogo universiteta.

Grechenko, T.N., \& Sokolov, E.N. (1979). Ėndonejronal'naâ plastičnost' izolirovannyh nejronov vinogradnoj ulitki [Endoneuronal Plasticity of Isolated Helix lucorum Neurons]. Žurnal vysšej nervnoj deâtel'nosti, 29 (5), 1093-1095.

Jensen, O., \& Tesche, C.D. (2002). Frontal Theta Activity in Humans Increases with Memory Load in a Working Memory Task. European Journal of Neuroscience, 15, 1395-1399.

Livanov, V.M. (1972). Prostranstvennaâ organizaciâ processov golovnogo mozga [Spatial Organization of Cephalic Brain Processes]. Moscow: Nauka. 
Mantini, D., Perrucci, M.G., Del Gratta, C., Romani, G.L., \& Corbetta, M. (2007). Electrophysiological Signatures of Resting State Networks in the Human Brain. PNAS, 104 (32), 13170-13175.

Posner, M.I. (2004). Progress in Attention Research. In M.I. Posner (Ed.), Cognitive Neuroscience of Attention (pp. 3-9). New York, London: The Guilford Press.

Sannita, W.G. (2000). Stimulus-Specific Oscillatory Responsess of the Brain: A Time/Frequency-Related Coding Process. Clinical Neurophysiology, 111 (4), 565-583.

Sarnthein, J., Petsche, H., Rappelsberger, P., Shaw, G.L., \& von Stein, A. (1998). Synchronization Between Prefrontal and Posterior Association Cortex during Human Working Memory. PNAS, 95 (12), 7092-7096.

Sauseng, P., Hoppe, J., Klimesch, W., Gerloff, C., \& Hummel, F.C. (2007). Dissociation of Sustained Attention from Central Executive Functions: Local Activity and Interregional Connectivity in the Theta Range. European Journal of Neuroscience, 25, 587-593.

Sauseng, P., Klimesch, W., Cruber, W.R., Hanslmayr, S., Freunberger, R., \& Doppelmayr, M. (2007). Are Event-Related Potential Components Generated by Phase Resetting of Brain Oscillations? Neuroscience, 146 (4), 1435-1444.

Sauseng, P., Klimesch, W., Gruber, W.R., \& Birbaumer, N. (2008). Cross-Frequency Phase Synchronization: A Brain Mechanism of Memory Matching and Attention. NeuroImage, 40, 308-317.

Singer, W., \& Gray, C.M. (1995). Visual Feature Integration and the Temporal Correlation Hypothesis. Annual Review of Neuroscience, 18, 555-586.

Sokolov, E.N. (1981). Nejronnye mehanizmy pamâti i obučenie [Neuronal Mechanisms of Memory and Learning]. Moscow: Nauka.

Sokolov, E.N. (2003). Vospriâtie i uslovnyj refleks: Novyj vzglâd [Perception and Conditional Reflex: New Approach]. Moscow: UMK "Psihologiâ."

Sokolov, E.N., \& Nezlina, N.I. (2007). Uslovnyj refleks i komandnyj nejron [Conditional Reflex and Command Neuron]. Žurnal vyš̌ej nervnoj deâtelnosti, 57 (1), 5-22.

Tallon-Baudry, C., Kreiter, A., \& Bertrand, O. (1999). Sustained and Transient Oscillatory Responses in the Gamma-Band and Beta-Band in a Visual Short-TermMemory Task in Humans. Visual Neuroscience, 16 (3), 449-459. 